\title{
AÇÕES AFIRMATIVAS E UNIVERSIDADE NO BRASIL
}

\author{
Paulo Gomes Lima ${ }^{1}$ \\ Universidade Federal da Grande Dourados -UFGD
}

\section{RESUMO}

A pesquisa problematiza as políticas de ações afirmativas como instrumento de inclusão social à universidade brasileira. Estabelece as relações entre a reestruturação produtiva, reforma de Estado e políticas educacionais; a educação superior no Brasil no contexto do modo-de-produção capitalista e seus arranjos históricos de exclusão social, apontando para a possibilidade de um terceiro olhar. Neste caso, são destacadas as relações entre o neoliberalismo, o trabalho e políticas compensatórias de acesso à universidade brasileira e os desafios contemporâneos para a inclusão social propriamente dita. O nível conceitual da investigação sustenta-se em quatro eixos: a) Mészáros, b) Habermas, c) Karel Kosik e d) Adorno \& Horkheimer. A pesquisa evidencia a necessidade de políticas públicas para a universidade no Brasil a partir de uma dimensão universal sustentada por uma lógica libertadora e humanizadora.

Palavras-chave: universidade brasileira, ações afirmativas, inclusão social.

\section{AFFIRMATIVE ACTION AND UNIVERSITY IN BRAZIL}

\begin{abstract}
The inquiry problematizes the politics of affirmative actions as instrument of social inclusion to the Brazilian university. Establish the relations between the productive restructuring, reforms of State and education politics; the superior education in Brazil in the context of the way of capitalist production and his historical arrangements of social exclusion, pointing to the possibility of a third glance. In this case, are pointed out the relations between the neoliberalismo, the work and compensatory politics of access to the Brazilian university and the contemporary challenges for the social inclusion properly stated. The level conceitual of the investigation is supported in four axles: a) Mészáros, b) Habermas, c) Karel Kosik and d) Adorno \& Horkheimer. The inquiry shows the necessity of public politics up for the university in Brazil from a universal dimension supported by a logical liberator and human.
\end{abstract}

Keywords: Brazilian university, affirmative actions, social inclusion

\section{Introdução}

A discussão de políticas de ações afirmativas no Brasil tomou maior vulto na década de 1990, período em que distintas problemáticas foram evocadas por movimentos sociais, em que vários desvios históricos em nível de academia foram denunciados na bipolaridade opressor-oprimido, inclusive no âmbito educacional, dentre os quais destacamos o acesso "consentido" à universidade brasileira por classes sociais desfavorecidas, incluindo nestas, os grupos étnicos historicamente marginalizados. O grande foco do capital

Este "acesso consentido" apresentado de maneira conveniente não propunha uma alternativa de transformação social consistente em si, mesmo porque a lógica do capital 
não seria rompida, uma vez que feria interesses de classe e as mudanças estruturais para a sua implementação não fora objeto que chamasse a sociedade para o debate social sobre as consequiências, implicações históricas e a contestação do capital como elementos geradores das desigualdades sociais, antes a questão foi tratada numa dimensão remediativa, preservando os interesses objetivos de classe, bem distinto do que poderia ser considerado democratização e universalização da educação superior. Assim a lógica de concessão e contenção permaneceu como elemento norteador da política e gestão da educação superior no Brasil.

Ao invés daquelas questões serem trazidas à tona com o objetivo de democratizar concretamente as condições materiais da sociedade como um todo e na universidade brasileira em particular, o que se projetou foi uma alienação acerca da problemática suscitada, revestida de um discurso corretivo das dívidas históricas em relação às populações socialmente menos favorecidas (negros, pobres, indígenas) e em nenhum momento foram suscitadas medidas concretas para o processo de humanização, democratização propriamente dita e universalização.

Vale destacar o sentido que estas três categorias assumem neste artigo, a saber, a humanização como a ação transformadora do homem e no homem a partir de sua autoprodução e não exploração de sua força de trabalho e à medida que constrói a sua história, que socializa de forma universalizada os bens culturais, políticos, econômicos e sociais; a democratização como processo de apropriação e participação comum nos e dos direitos civis, políticos e sociais, no caso da universidade em nível de acesso, condições de permanência e garantia de continuidade em níveis mais elevados de ensino; a universalização pelo sentido da equidade, igualdade e justiça social para todos os homens.

Entretanto, o sentido que as políticas de ações afirmativas assumiu, no caso brasileiro, contribuiu celeremente para o quadro do sociometabolismo do capital no processo de reestruturação produtiva, consequentemente, preservou-se a inalterabilidade da estrutura e arranjos sociais, enquanto que as discussões se davam de maneira muito setorializadas e convenientemente orientadas entre os favoráveis às políticas de cotas e os contrários. A diretriz para se pensar as ações afirmativas no Brasil de acesso à universidade não trazia à tona outra discussão ou qualquer outra alternativa para o encaminhamento da problemática, limitando as "novas políticas educacionais" entre o 'sim' e o 'não' de maneira antagônica e conformada. Neste âmbito, percebemos que algumas indagações e encaminhamentos seriam necessários para problematizarmos este eixo dualista. Tal inquietação à luz da triangulação: universalização, humanização e democratização da educação superior no Brasil, contribuiu para a construção de nossa problemática de pesquisa por meio de uma pergunta orientadora, a saber: "O posicionamento "favorável" ou "desfavorável" às políticas de ações afirmativas no âmbito universitário brasileiro garantiria a universalização, humanização e democratização de acesso ao conhecimento como elementos afrontadores da lógica do capital?"

A universidade no Brasil a partir de uma dimensão universalizada sustentada por uma lógica libertadora e humanizadora e a evocação da legitimidade de um terceiro olhar sobre as solicitações sociais acerca da universidade favoreceram o descortinamento da problemática transversalizadas pelos eixos conceituais: a) as práticas dissimuladoras na centralidade capital-trabalho (Mészaros), b) o agir comunicativo na determinação da ação histórica (Habermas), c) A mobilização concreta do homem na história e com a história (Karel Kosik) e d) o antagonismo entre o particular e o universal (Adorno \& Horkheimer). O itinerário investigativo destaca a recorrência de um olhar que possibilite ao cidadão brasileiro, mobilizar-se na história e com a história no sentido mais amplo de atuação social, deflagrando a denúncia da lógica capitalista neoliberal e seu poder alienador da 
dimensão universal, libertadora e humanizadora de acesso à universidade brasileira na busca de encaminhamentos e ações concretas que viabilizem a construção de uma outra estrutura social.

\section{Reestruturação produtiva, reforma do Estado e políticas educacionais}

A estruturação produtiva nos países capitalistas assumiu esta lógica de polarização entre classes sociais, predominando um discurso ideológico em sentido restrito que, embora não se mostrasse tão explícito quanto aos seus objetivos reais (por conveniência), era, no mínimo, coerente em relação a defesa de seu ideário, obviamente de forma velada, a saber, a expropriação de direitos do cidadão e controle para uma sociedade liberal direcionada ao consumo e expansão globalizada do mercado capitalista e à clássica defesa da divisão internacional do trabalho.

O Estado brasileiro a partir da década de 1930, tomando como diretriz a sua integração ao capitalismo internacional por conta da inauguração da fase urbano-industrial, observará, a partir daí, a fusão de seus interesses aos monopólios privados e internacionais marcada inicialmente pela importação dos bens de produção e encampamento ao modelo fordista de produtividade/produção da estruturação produtiva liberal.

Face ao discurso do nacional desenvolvimentismo e financiamentos internacionais nos anos 50 e 60, o Estado brasileiro buscava substituir as importações dos bens de produção e uma expansão industrial entre os diferentes setores de produção que pudessem favorecer as exportações de produtos industrializados por meio de transferências de excedentes do setor agroexportador para o industrial privado, inviabilizando o financiamento das empresas estatais e resultando numa retração das exportações.

Ao capital estrangeiro tal retração era muito significativa, uma vez que o empresariado brasileiro recorria ao mesmo em busca de investimentos diretos ou indiretos, concentrando rendas e propiciando medidas econômicas institucionais de livre controle do mercado. Este quadro apontava para duas realidades segundo Xavier (1990, p.53-54), a saber: a) do ponto de vista da realidade interna, o impedimento da integração nacional e absorção da ideologia capitalista e b) do ponto de vista da realidade externa, estímulo à modernização sim, mas com o impedimento do desenvolvimento auto-sustentável. Neste contexto, em que as relações de poder dão estabilidade aos privilégios das classes hegemônicas no Brasil e em que o capital internacional se "legitima" como necessário à visibilidade econômica do Brasil, o nacional-desenvolvimentismo entra em colapso. A dimensão norteadora apontava o mercado como regulador da economia, marcando a expropriação histórica dos detentores da força de trabalho. A demanda educacional seguirá orientada por esta lógica, na formação de um homem determinado para uma sociedade condicionadora de interesses da internacionalização do capital.

Enquanto o Brasil, em sua estruturação produtiva incipiente, está imerso no "adestramento" tardio do capitalismo internacional; observa-se, na década de 1970 a solicitação da lógica do mercado capitalista evocando não somente maior expansão de mercados, mas uma reestruturação produtiva deflagrada pela constatação da falência do modelo fordista/taylorista, compassado pela baixa produção e produtividade industrial e resultando em redução de níveis de expansão do capital, tendência decrescente da taxa de lucro e crise do Welfare State ou Estado de Bem-estar social, que gerou a crise fiscal do Estado capitalista. Esta instabilidade liberal ainda seria agravada pela crise do petróleo de 1973, substancial elevação das taxas de juros americanas em 1979 (gerando protestos de conglomerados do empresariado capitalista internacional) e crise da dívida externa dos países da periferia do capitalismo. 
A reestruturação produtiva sob inspiração do capital transnacional apontava como ponto consolidado à crise do modelo fordista, o parâmetro neoliberal. O neoliberalismo, muito mais do que prescrições para as economias capitalistas, caracterizava-se como filosofia equalizadora de índole social-democrata, inclusive na supressão de desigualdades sociais e redistribuição de renda. O termo em si, neoliberal, não será o preferido pelas economias e mercados capitalistas e sim e o de "social democracia" pela abrangência de seu alcance social e econômico na totalização do desenvolvimento das nações. A inspiração do modelo neoliberal se dá inicialmente no Chile, quando da derrubada do governo socialista de Allende em 1973 e depois nos governos de Margareth Thatcher (Inglaterra) e do governo republicano de Ronald Reagan (EUA), cujos pressupostos inundaram o mundo capitalista nos anos de 1980 por meio da operacionalização de medidas neoliberais (Lima, 2005).

O Brasil somente não cumpriu de pronto tal agenda neoliberal por conta da projeção dos movimentos sociais e trabalhistas que eram muito intensos na década de 1980, entretanto, viu-se a sua introdução a partir do governo de Fernando Collor de Melo, interrompida temporalmente pelo impeachment e o governo breve de Itamar Franco, mas retomada com todo o vigor no governo de Fernando Henrique Cardoso em suas duas gestões, deslegitimizando os sindicatos, promovendo privatizações e desarticulando as reivindicações de movimentos sociais, a exceção do MST (Movimento dos Trabalhadores Rurais Sem-Terra).

Esta reportação é muito oportuna quando consideramos a totalidade do programa de governo de FHC nos anos de 1990 e sua proposição frente a reforma de Estado que, de forma geral, do início ao fim do governo, em nome da "social democracia" adotou quase que unanimemente as primeiras diretrizes neoliberais operacionalizadas por Margaret Thatcher, a saber: elevação das taxas de juros, diminuição significativa sobre os rendimentos altos, abolição de controle sobre os fluxos financeiros, geração de níveis massivos de desemprego, sufocação de greves, imposição de legislação anti-sindicais, corte de gastos sociais e por último, mas não menos importante, um acentuado programa de privatização; têm sido em maior ou menor intensidade o programa de governos neoliberais.

Neste sentido, embora os discursos explicitem até a preocupação com o bem estar social, o que vai predominar em tais economias é exatamente a ortodoxia neoliberal por meio do controle social, expansão do capital, mercado abundante de mão-de-obra (neutralizando as ações sindicais) e medidas que atenuem ou deixem de enfatizar o pleno emprego e concessões fiscais àqueles que detêm o capital financeiro. Neste sentido para que a reestruturação produtiva alcançasse sucesso nos países capitalistas (neoliberais) seriam necessários investimentos maciços em setores de ponta (informática, química, biotecnologia, dentre outros) e modernização de setores dinâmicos (automobilístico, produtos, processos), novos padrões de organização e gestão do trabalho (modelo just-intime), automação dos processos produtivos e controle dos sindicatos, mudando a lógica capital-trabalho. Neste caso, cumpre observar que a tipologia de homem para a sociedade neoliberal exigia que se cumprisse uma preparação e qualificação constantes entre competências e habilidades, assim a escola em todos os seus níveis também deveria ser revisitada para a nova agenda da economia mundial.

Com a vitória de Fernando Henrique Cardoso nas urnas em 1994 e o seu empossamento em 1995 como presidente do Brasil, veio a tona uma veemente cobrança acerca de um dos seus ditos acerca de uma necessária e urgente reforma do Estado. Assim, o ponto nevrálgico que conduziria a arrumação da casa nos seus distintos setores estava na perspectiva desta reforma de cunho político, fiscal e institucional. Tal reforma apontada 
cria-se, contribuiria para a projeção do país como promissor em investimentos e adequado à nova ordem econômica mundial pautada pela globalização, tendo o desenvolvimento tecnológico como elemento desencadeador deste processo. $\mathrm{Na}$ visão do governo tucano ${ }^{2}$ isto seria possível tangendo duas dimensões que se convergiam: a adequação às pressões externas da internacionalização das economias e dos mercados e o atendimento às demandas da sociedade. Segundo esta perspectiva havia que se mudar de modelo de administração, pois a administração pública brasileira, centrada em interesses particularistas, clientelistas e fisiológicos, desde a era Vargas pós-30 e consolidada nos governos posteriores era a principal causa apontada pelo atraso histórico do desenvolvimento do Brasil como potência econômica.

A lógica era a de que o próprio governo deveria acompanhar as novas formas de produção e organização de trabalho em nível mundial rompendo com os pressupostos weberianos de administração burocrática e com os tradicionais modelos taylorista/fordista, provendo a requalificação do trabalho e do trabalhador sob uma perspectiva que acompanhasse a nova dinâmica econômica e social. Segundo Bresser Pereira (1996) a reforma de Estado proposta pelo governo FHC não era neoliberal, muito pelo contrário, era a de uma social democracia, pois não tinha o objetivo de tirar o Estado da economia, mas o de favorecer a sua governança mediante recursos financeiros e administrativos, rompendo com a crise do Estado deflagrada desde o governo militar. Como apontava Chauí (2000), existem muitos campos velados dentro do discurso neoliberal, mesmo quando da negação da índole do próprio discurso, afirmando-o como social democrata de cunho keynesiano, e negando-o efetivamente no reparo histórico da economia brasileira, irá se orientar pela demanda da ordem capitalista mundial distanciando-se do que se entende como social democracia propriamente dita.

Todo o esforço das diretrizes neoliberais materializou-se certamente nas políticas educacionais do Brasil, implicando a incorporação de problemáticas sociais e redefinição do papel da Educação Básica na erradicação dos problemas sociais. Desta forma, a geração das desigualdades, fome, desemprego, preconceitos passam a ser temas amplamente discutidos na sociedade mundial como fatores agravantes do desenvolvimento econômico, subtraindo possibilidades de uma sociedade que deve primar pela redistribuição de renda e a promoção da justiça social. A educação voltada para as classes trabalhadoras deveria ter como papel precípuo o de correção das desigualdades sociais, o Estado exime-se da responsabilidade direta pelo desenvolvimento econômico e social atuando como regulador do mesmo (BRASIL, 1996).

Vê-se que as políticas educacionais, a partir da reforma do Estado, seriam confundidas ou convenientemente orientadas com políticas sociais, como medidas corretivas para uma problemática gestada pelas "circunstâncias", não identificadas como de responsabilidade do mesmo Estado. A cargo desta correlação entre investimentos em educação e políticas sociais, organismos multilaterais como o Banco Mundial, atrelam as correções de dívidas sociais históricas como um novo paradigma que favorecerá o desaparecimento dos bolsões de pobreza no mundo.

Para Coraggio (1996, p.86) a lógica do novo arranjo do mercado capitalista internacionalizado, explica o porquê de o Banco Mundial destacar-se, principalmente na década de 1990, como agência promotora de investimentos em setores sociais, bem como na reorientação de diretrizes educacionais em todos os âmbitos, centradas no mesmo foco. Tal orientação centra seus esforços na oferta de uma categoria circunstanciada de "qualidade da educação", marcada por ações paliativas, mas que apresenta o Estado como agente promotor de visibilidade do país, coerente com as demandas internacionais. 
Enfatiza-se que a reestruturação produtiva orientada pelo novo arranjo da lógica capitalista globalizada e a reforma do Estado, iniciada na década de 1990 serão os delimitadores das políticas e propostas educacionais em atendimento aos requisitos da regulação do mercado, conseqüentemente, para a formação de uma tipologia de cidadão pertinente aos anseios da sociedade neoliberal. Incluso neste quadro estariam arranjos paliativos para correção de fluxo à universidade e a defesa da inclusão social como saída para a resolução de dívidas históricas. No caso brasileiro, esta dimensão solicita a compreensão da Educação superior no contexto do modo de produção capitalista e seus arranjos históricos de exclusão que, evidentemente, transitando entre o pré-capitalismo e o capitalismo com nova roupagem, não tratará da universalização, democratização e humanização do acesso à universidade como projeto prioritário, dada a sua orientação elitista, como analisaremos a seguir.

\section{Educação superior no Brasil no contexto do modo-de-produção capitalista e seus arranjos históricos de exclusão}

A educação no Brasil desde sua implantação fora explicitamente voltada ao controle social por meio do poder político e para a formação de elites pertinentes. Inicialmente com a organização de estudos em duas dimensões ainda na colônia: Studia Superiora (formação dos sacerdotes) e Studia Inferiora (equivalente ao ensino secundário ou propedêutico à universidade) pela Companhia de Jesus e a posteriori nos distintos arranjos políticos organizacionais que iriam se seguir. Nos primeiros séculos do período colonial ainda não podemos falar de ensino superior no Brasil, uma vez que, em nível de aprofundamento era na metrópole portuguesa e demais países europeus que ocorria a oferta desta modalidade de ensino.

O que havia de fato eram os colégios religiosos mantidos pelos jesuítas que oferecia formação para o sacerdócio ao mesmo tempo em que preparação para continuação dos estudos dos filhos dos latifundiários e comerciantes, mas mesmo esta estrutura seria desmantelada por conta da expulsão dos jesuítas no Brasil, sem ferir em profundidade os interesses educacionais da elite, uma vez que a educação tutoriada era uma praxe da classe. Somente no Império é que se consubstancia a inauguração do Ensino Superior e o preparo dos "cidadãos" do império para assumirem funções no serviço público, excluído e expropriado deste arranjo, o povo.

No final do império do Brasil, a demanda por ensino superior cresceu significativamente como via de ascensão social mobilizada pela necessidade de formação de quadros administrativos pelo Estado, pelo ideário da elite de que o ensino superior favoreceria o desenvolvimento da educação, ciência e tecnologia e com isto ocorreria o desenvolvimento econômico e social do país e, finalmente pelo status pessoal conferido a um diplomado, ao chamado "doutor". Esta demanda era situada entre a elite latifundiária e as classes ascendentes, uma vez que, o "interesse geral da nação", validado pelo Ato Adicional de 1834, quanto à educação, direcionava-se ao Ensino Superior, enquanto que outras demandas para a educação, como a escola de primeiras letras, eram de responsabilidade das províncias.

Destaca-se que a responsabilidade pela criação de instituições de ensino superior, bem como a nomeação dos catedráticos era do Estado até que em 1879, por meio da Reforma Leôncio de Carvalho, foi conferida à liberdade de ensino e pesquisa para instituições de ensino superior particulares, com a proibição destas instituições se oporem aos princípios da religião católica, já que se tratava da religião oficial do império. Esta restrição, bem como da aprovação dos professores para as instituições particulares, seria 
eliminada gradativamente face aos interesses de representantes de outras religiões, vindos de outros países e que aqui residiam, como por exemplo, os ingleses, que mantinham fortes aproximações com o Brasil por meio do comércio internacional. Podemos dizer que os interesses religiosos tiveram que se adequar às projeções do mercado capitalista que aos poucos começava a ganhar outras feições. Entretanto, a maioria do povo estava à margem de qualquer oportunidade educacional no que tange à educação elementar, pior ainda no âmbito da educação superior dado aos fortes "apelos meritocráticos dos bem-nascidos" na ocupação das vagas disponibilizadas.

Com a proclamação da república em 1889 mediante um golpe de Estado no desfecho de uma conspiração que reuniu liberais, positivistas e monarquistas ressentidos, tal preferência pelo ensino superior de elite não muda, pelo contrário, se dizia que não haveria impedimentos para as classes desfavorecidas ascenderem à escola em seus níveis mais elevados, mas nenhum arranjo político materializava tais dizeres na universalização de condições e acesso à escola primária e muito menos à universidade. Discursos e mais discursos ufanísticos se sucediam "pintando" a educação como redentora do país como resposta única ao seu atraso econômico e social no recém- regime presidencialista, não redundando em qualquer medida efetiva ou projeção de abertura, acesso, universalização, democratização ou universalização da oferta educacional no Brasil.

Vai haver por conta dos avanços dos liberais no início da república efusiva busca pelo ensino superior, o que seria respondido pela sociedade elitista, por meio de contenção - universidade não para todos, mas para os "merecedores". Estas buscas extrapolavam o interesse da classe senhorial (que ainda era muito forte). Desta forma, por meio da reforma Carlos Maximiliano (1915) - houve uma reoficialização (Lei Orgânica Rivadávia Corrêa de 1911 desoficializava o ensino superior- propondo autonomia didática e administrativa para as instituições - acabando com o privilégio estatal de concessão de diplomas e títulos) do ensino superior consolidando as tradicionais tendências elitistas do ensino nacional Foi nesta reforma que surge o exame vestibular no Brasil, intensificando e legitimando o processo histórico de exclusão educacional no contexto do modo de produção capitalista.

Esta concepção organísmica do ensino superior não mudaria, mesmo com a criação legal da universidade no Brasil que se deu mediante o Decreto n. ${ }^{\circ} 11.530$ no seu artigo $6^{\circ}$, datado de 18 de março de 1915. A proposição básica deste decreto pressupunha a reunião da Escola Politécnica, da Faculdade de medicina do Rio de Janeiro e uma das Faculdades livres de Direito. Tal proposição só se concretizaria através do Decreto $\mathrm{n}^{\circ} 14.343$ de 7 de setembro de 1920, portanto, cinco anos depois da "criação legal" da universidade no Brasil, com o surgimento da Universidade do Rio de Janeiro, a primeira instituição universitária criada pelo governo central, cuja existência deu-se, mais por um caráter político do que como uma necessidade de expansão do conhecimento, haja vista que as unidades que a formavam apresentavam pontos conflitantes e unilaterais.

Entretanto, mesmo sendo a partir de um início equívoco e conturbado, foi mediante este marco que a universidade brasileira estabeleceu seu processo de construção. Um dos fatos que revelava tal processo deu-se através da abertura de debates nos anos de 1922 e 1927 respectivamente, convocados e promovidos pelo próprio governo federal e, nos anos de 1926 e 1928 ocorreram inquirições ou inquéritos promovidos pela Associação Brasileira de Educação (ABE) e o jornal "O Estado de São Paulo". Os temas debatidos e inquiridos, principalmente nestas últimas datas, versavam sobre a realidade do ensino superior brasileiro, a missão e a função da universidade, cuja ênfase centrava-se na questão da unidade fundamental das ciências e à abertura para investigações e descobertas (SILVEIRA, 1987, p. 21) e na discussão indagativa que, a posteriori, influenciaria os rumos da universidade brasileira, adentrando até questões de caráter epistemológico: 1) por 
quais caminhos seguir? 2) que medidas (políticas, sociais, culturais) seriam necessárias para orientar a emergente universidade (que nascera equivocamente) que estava a procura de sua própria identidade? e 3) sobre quais perspectivas epistemológicas seriam assentadas as bases da universidade brasileira?

Dito de outra forma, estavam procurando um modelo a ser seguido, uma via que pudesse ser adaptada à universidade no Brasil (assim como foram incorporados os modelos da política educacional francesa e a posteriori, os da alemã por ocasião da reação alemã à invasão napoleônica), neste ínterim, o povo acompanhava extasiado e distanciado dos novos arranjos na educação superior brasileira. Destas inquirições e debates, a idéia de se adotar os modelos europeus e norte-americanos de política educacional no ensino universitário era a tônica em evidência, principalmente no que tangia ao modelo norteamericano, uma vez que se voltava à formação do profissional (o que não diferia muito do sistema empregado nas faculdades brasileiras isoladas) para o mercado de trabalho (tal modelo de universidade, era respaldado por uma base empírica positivista). Assim, tais argüições nas décadas de 20 e 30 (séc. XX) resultaram no delineamento da idéia de universidade que seria implantada no Brasil, não apenas com uma finalidade puramente didática, mas também voltada para o campo social e atendimento da demanda de classe, suprindo o mercado de trabalho com os profissionais "necessários" à realidade brasileira; isto se deu através da Reforma Francisco Campos no ano de 1931 (Decretos n. ${ }^{\circ} 19.851$ e n. ${ }^{\circ} 19.852$ de 11 de abril de 1931).

Assim nasce a Universidade Brasileira, tendo como espelho a estruturação do sistema universitário europeu e norte-americano, cuja influência perpassaria o Estado Novo (1937-1945) e a República Populista (1945-1964). Lembrando que, neste último período, levando-se em consideração o acirramento das contradições existentes no momento político e, particularmente no seio da universidade e esta sofrendo um duplo processo crítico (indefinição sócio-pedagógica e crítica) de si mesma, o apelo para a modernização do ensino superior era veemente e expressivo em direção do modelo norteamericano (este não era um apelo novo, mas o resgate das aspirações de intelectuais que o propalou desde os anos 20 e 30). Para que tal evento se deste institucionalmente o quadro político-econômico do governo estava bem traçado, haja vista a expressiva influência norte-americana através dos acordos MEC-USAID, orientando, com a conivência governamental, a universidade brasileira, segundo a estruturação da norte-americana. A este respeito Cunha (1988) afirma que a estrutura administrativa e pedagógica das universidades norte-americanas era enaltecida como modelo a ser seguido. Dela se propunha copiar ou adaptar vários aspectos como, por exemplo, os colleges e os teacher's colleges.

O curso de graduação deveria ser fragmentado em três: o bacharelado superior, a licenciatura e o doutorado". Tal caminho referencial culminaria na gestação política da reforma universitária de 1968 (Lei $\mathrm{N}^{\circ}$ 5540). E anterior a este momento na própria estruturação da produção científica no Brasil através dos programas de pós-graduação (parecer 977/65). O Brasil, em meio ao governo militar, ratificava sua opção pela educação superior não universalizada, mas com a projeção de criação de nichos tecnológicos com investimentos em mentes preparadas para isto. Vale destacar que o período que vai de 1968 a 1980, marca a inauguração da incipiente Política de Ciência e Tecnologia para o Brasil nos conturbados governos militares (também dos acordos MEC-USAID) que haviam se instaurado, mobilizada por condicionantes adversos, como por exemplo o "milagre econômico", versus crise econômica e introdução à "década perdida" (1980), mas que traria muitas manifestações sociais por meio de movimentos organizados na denúncia do jogo político, orientado pela arbitrariedade do regime e de propostas 
contraditórias que excluíam as classes sociais menos favorecidas das oportunidades educacionais e sociais, mesmo que os discursos pretendessem explicitar o contrário.

Assim, nas décadas de 70, 80 e 90, medidas paliativas são desenhadas pelo governo brasileiro à medida que ocorrem movimentos sociais organizados em busca de inserção no mundo universitário, no intuito de amainar os conflitos. Alguns exemplos que podem ser explicitados neste aspecto são: a abertura de crédito estudantil (o que nos anos do governo Lula seria solidificado por meio do FIES - Financiamento Estudantil) para estudantes de classes desfavorecidas, a expansão de universidades privadas para atender demandas que o setor público não atendia, e na década de 90 , inicia-se a discussão e implantação de ações afirmativas por meio da política de cotas à universidade brasileira. Vale destacar que o PROUNI (Programa Universidade para Todos), cuja finalidade centrava-se na concessão de bolsas parciais e integrais à estudantes de graduação que não tivessem condições de pagar uma universidade privada, que fora projeto do governo de Luís Inácio Lula da Silva, também centrava-se na lógica de políticas compensatórias. Entretanto, a seguir, por conta de nosso objeto de estudo, contextualizaremos as ações afirmativas no Brasil veiculadas como instrumento direcionado à inclusão das classes menos favorecidas à universidade.

\section{Ações afirmativas no Brasil como instrumento de inclusão das classes menos favorecidas à universidade: pontos, contrapontos e a possibilidade de um terceiro olhar}

Em âmbito geral, as políticas de ações afirmativas têm sido entendidas como meio de beneficiar grupos socialmente desfavorecidos na consecução de recursos escassos em distintos âmbitos dos arranjos sociais, inclusive na universidade. Com o fim do período militar e o processo de redemocratização no Brasil, muitos movimentos sociais começaram a se mobilizar em busca das correções de dívidas sociais historicamente situadas, principalmente entre 1989 e a década de 1990. Para que compreendamos como se procedeu este itinerário consideraremos para discussão três pontos tomando as ações afirmativas como eixos de recorrência: pontos de correção de dívida histórica, contrapontos acerca da discriminação positiva e a possibilidade de um terceiro olhar entre pontos e contrapontos.

Em meio à construção da problemática não nos parecia coerente simplesmente nos colocar contra ou a favor da principal discussão do dia: ações afirmativas encampadas por políticas de cotas na universidade brasileira; nem mesmo nos manter omissos e passivos diante de um momento histórico que solicitava recorrências norteadas por um olhar críticoreflexivo, desta maneira assumimos a orientação de problematizarmos as condições em que se propunham tais ideários no seio de uma sociedade capitalista. Por meio de levantamento bibliográfico, identificamos que em pleno governo FHC, em 1996, ano da inauguração da LDB 9394/96, fora constituído um Grupo de Trabalho Interministerial para a Valorização da População Negra, que como orientação definia "ações afirmativas" como medidas especiais e temporárias, tomadas pelo Estado com o objetivo de eliminar desigualdades historicamente acumuladas, garantindo a igualdade de oportunidade e tratamento, bem como de compensar perdas provocadas pela discriminação e marginalização, por motivos raciais, étnicos, religiosos, de gênero e outros. (BRASIL, 1996)

O amplo espectro marcado pelas intervenções neoliberais do governo de então denunciavam o percurso de suas "concessões" ou "aberturas consentidas" e nomeadas de "medidas especiais e temporárias", que não se firmavam como conquista histórica do povo brasileiro, principalmente no tocante ao ingresso à universidade, mas "tomadas pelo Estado", para que por meio de deliberações fossem eliminadas as desigualdades sociais 
historicamente acumuladas. Propunha-se uma correção da dívida histórica com os grupos e classes sociais marginalizados por meio da "inclusão social".

Neste projeto não havia espaço para se articular outro olhar ou arranjo social em que não houvesse excluídos, mas o panorama era o de, mantendo-se o projeto histórico da universidade para poucos no Brasil, as medidas inclusivas, a exemplo do modelo norteamericano por meio das ações afirmativas, atenuariam as questões situadas pelos movimentos sociais. Neste quadro é que as ações afirmativas serão propostas com maior ênfase neste período, com o cuidado de não evidenciar os interesses e arranjos capitalistas de forma explícita, daí o incentivo governamental estendido, inclusive, à própria universidade na ênfase de discussões que geraram posicionamentos contrários ou favoráveis à temática, mesmo porque independentemente de qualquer direcionamento, os interesses neoliberais não seriam abalados, apenas tiveram o seu foco desviado.

Apenas a exigência do reconhecimento das desigualdades sociais, econômicas, culturais... é suficiente para a realização da igualdade? Em si não. Outros elementos que não os remediativos (pois não têm o propósito de erradicação e universalização) poderão favorecer uma resposta em nível amplo e abrangente. Porém, antes de apresentá-los é necessário contextualizarmos as ações afirmativas como "discriminação positiva", e através desta, a pretensão de se dar por resolvido o encaminhamento das desigualdades sociais.

Em 1965 as Nações Unidas aprovam a Convenção sobre a Eliminação de Todas as Formas de Discriminação Racial, da qual o Brasil passou a ser asignante desde 1968. Nesta Convenção (no artigo $1^{\circ}$, parágrafo $4^{\circ}$ ) foi estabelecido que "medidas especiais e temporárias" fossem adotadas para proteção, incentivo, equiparação de grupos sociais menos favorecidos às mesmas oportunidades que os grupos socialmente favorecidos. Tais medidas foram denominadas de "discriminação positiva" (ações afirmativas), isto é, o reconhecimento e a abertura de inclusão social dos grupos identificados como maneira de correção das dívidas históricas causadas por preconceitos em todas as suas formas.

Em muitos trabalhos acadêmicos a adoção das ações afirmativas como "discriminação positiva" tem sido considerada como uma evolução cultural e humana que, finalmente o Brasil se deu conta na correção de sua dívida histórica, principalmente quanto à exclusão do negro das universidades e oportunidades sociais. Assim a questão da discriminação positiva é encaminhada como uma forma de promoção da "justiça" historicamente situada, esquivando-se de outra leitura necessária a da noção de equidade necessária. Não se promove a equidade, mas se exclui grande contingente das ditas oportunidades sociais, gerando-se outras “injustiças históricas”. Tais discriminações positivas tão profusamente defendidas no Brasil se originaram nos EUA para amenizar conflitos entre o movimento negro e o controvertido inimigo dos direitos civis - Nixon. Acrescente-se que a este respeito vale lembrar Kaufmann (2009):

[...] percebe-se que uma das ironias sobre a criação das ações afirmativas é que estas foram imaginadas e colocadas em prática por alguns brancos que estavam no poder. Do contrário, os principais líderes do movimento negro organizado não se manifestaram favoravelmente a uma política integracionista, mas lutaram apenas para combater a discriminação institucionalizada. Martin Luther King chegou a se manifestar sobre o tema, advertindo que a adoção de políticas afirmativas seria contraproducente para o movimento negro, porque não conseguiria encontrar justificativas diante de tantos norte-americanos brancos pobres. Com efeito, nunca houve uma marcha para Washington em favor dessas 
medidas, nem mesmo pressão política consistente e relevante a favor de cotas ou de mecanismos de integração.

A questão colocada como "discriminação positiva" como medida inclusiva, não responde significativamente ao grau de excludência do grande contingente de expropriados em relação ao ensino superior e aos demais bens materiais e sociais, porque trata-se de pontualidades que "concedem" o gozo do exercício cidadão em percentagens, ao mesmo tempo que num processo de contenção, assegura o direcionamento cidadão à classe hegemônica do capital. É sabido que os movimentos sociais têm encampado expressiva contribuição na discussão de tal quadro e alcançado espaços que dantes não eram ao menos pensados, entretanto, o que fragiliza tais "negociações" é a circunscrição de tais conquistas, o que muitas vezes parece dar um rosto de humanidade para a estrutura social do capitalismo, transvestido de uma solidariedade que não lhe é própria e nem o será, dada a sua correlação com os interesses de classe que representa, ao contrário, daí a necessidade de como povo organizado buscar-se a universalização dos direitos civis, políticos e sociais, dos quais a educação superior figura como nível de fundamental importância.

É possível pensar a transformação social qualitativa no seio da universidade brasileira contemporânea, asignante do modo-de-produção e apropriação capitalista que convencem e atrai cada vez mais adeptos aos seus postulados? Se não, que caminhos concretos podem favorecer a discussão e materialização da inclusão educacional, propriamente dita, à universidade e sob quais parâmetros? Lembrando Maria Abádia da Silva (2002, p. 175) as políticas educacionais no Brasil, de forma geral caracterizam-se pelo consentimento naturalizado desta dinâmica, atentando para: a) supressão da concepção de direito; b) explicitação de sua natureza contencionista-reformista, compensatória e discricionária; c) valorização de resultados estatísticos (ênfase no retorno dos investimentos capitalistas efetuados); d) incorporação de estratégias que reforçam o deslocamento das decisões do âmbito público para o privado; e) hierarquização das instituições escolares e acadêmicas; f) estimulação do setor privado para decisões, gerenciamento e execução, g) indução para que as instituições educativas assemelhem-se à lógica empresarial, h) priorização dos critérios econômicos e redução da educação à formação para o trabalho.

Sob esta materialidade histórica evidenciada, a partir de um terceiro olhar, poderemos problematizar os pontos de tensão da proposição das ações afirmativas no Brasil por meio de cotas à universidade. Este exercício vai nos solicitar a clarificação de que, de fato, a influência do modo-de-produção capitalista e a lógica de seu ideário neoliberal são impulsionados pela racionalidade de uma indústria cultural (SILVA, 2006; PESCE, 2007; MÉSZAROS, 2005) que apresenta um significativo alcance (mesmo sem o desvelamento das tramas neoliberais), das possibilidades e limites da inclusão educacional à universidade brasileira (SANFELICE, 2006; MESZÁRÓS, 2005; 2006; 2007), apregoando a globalização, a unidade na diversidade e negando a efetivação de desdobramento de conquistas sociais mais amplas.

Ao considerarmos o crescimento da adesão às ações afirmativas na universidade brasileira, podemos constatar que, embora a ideologia hegemônica veicule propostas para a inclusão educacional e encontre respaldo, por conta da expropriação histórica dos direitos, como observa Sanfelice (2006), os seus limites são estruturais. Assim, pensar a universidade brasileira e algumas políticas públicas de inclusão, a partir de uma sociedade capitalista democrática, não pontuando as relações entre neoliberalismo, trabalho e políticas compensatórias de acesso à universidade, fundantes das desigualdades, é ignorar o discurso ideológico forjado por uma burguesia que ratifica sua dominação pela violência simbólica. 
A partir da década de 1990, período em que no Brasil as políticas de inclusão educacional são mais evidentes, intensifica-se o discurso neoliberal, cuja viabilização se daria por conta da ruptura das economias nacionalistas, ratificando a internacionalização da mesma - mas entre os muitos sentidos dos discursos, cuja proposta neoliberal do capitalismo moderno explicita-se no combate a todas as formas de degradação da pessoa humana e sua respectiva valorização como cidadão do mundo, delineia-se o desvelamento de uma análise mais proximal deste quadro que denuncia esta lógica capitalista, cujos objetivos implícitos são perceptíveis na advogação de interesses particularizados.

Todo este conjunto ideológico tem sido operacionalizado como refrão para a solução das questões econômicas e sociais dos países capitalistas desenvolvidos ou em desenvolvimento, tendo como parâmetro, o controle ou extinção de mecanismos ou instituições que reivindicam melhorias salariais para os operários e seus interesses mediados por sindicatos em nome da retomada do crescimento econômico e controle inflacionário, sendo este conjunto efetivamente um norteamento do neoliberalismo desde a sua gênese.

Anderson (2000, p.12) lembra que quase que unanimemente as primeiras diretrizes neoliberais operacionalizadas por Margaret Thatcher, a saber: elevação das taxas de juros, diminuição significativa sobre os rendimentos altos, abolição de controle sobre os fluxos financeiros, geração de níveis massivos de desemprego, sufocação de greves, imposição de legislação anti-sindicais, corte de gastos sociais e por último, mas não menos importante, um acentuado programa de privatização; têm sido em maior ou menor intensidade o programa de governos neoliberais. Neste sentido, embora os discursos explicitem até a preocupação com o bem estar social, o que vai predominar em tais economias é exatamente a ortodoxia neoliberal por meio do controle social, expansão do capital, mercado abundante de mão-de-obra (neutralizando as ações sindicais) e medidas que atenuem ou deixem de enfatizar o pleno emprego e concessões fiscais àqueles que detêm o capital financeiro e ações de contenção de manifestações sociais por meio de " medidas especiais e temporárias", inviabilizando o processo de universalização, democratização e humanização de direitos.

Na sociedade contemporânea, globalizada e excludente, o estudo sobre a inclusão educacional não pode ser descontextualizada da centralidade capital-trabalho (MÉSZÁROS, 2005) pelo risco da conivência com um discurso e práticas dissimuladoras produzidas pelo metabolismo social do capital. Neste sentido entendemos a proposição da inclusão educacional, por meio de ações afirmativas, no caso da universidade brasileira através de cotas, como um objeto não isento à esta centralidade, solicitando o desvelamento das contradições e complexidades que não imiscui e nem minimiza os conflitos e debates entre luta de classes, identidade da cultura brasileira e superação de desigualdades por meio de transformação social qualitativa no seio da universidade, que problematizamos neste Trabalho.

Portanto, mediante um terceiro olhar sobre este debate atual, entendemos que a nota tônica não é, como já afirmamos colocar-se a favor, caminho que incorpora acalorados discursos no interior da universidade brasileira e encontra uma forte ecoação em movimento sociais e nem mesmo reunir posições contrárias simplesmente, como que adotando um posicionamento conservador da institucionalização históricas na universidade, pelo contrário, é problematizarmos a motivação do capital global que intensifica suas investidas, inclusive no âmbito de políticas sociais, tornando o seu poder muito mais legítimo do que a força e as necessidades reais dos Estados Nacionais.

As políticas compensatórias ou de ações afirmativas surgidas nos EUA e adotadas em vários outros países, como o Brasil estão em consonância com esta lógica capitalista, 
isto é, são elaboradas, desenvolvidas e implementadas pelo Estado para conter ou minimizar as "distorções sociais" não no sentido de promoção da justiça social universalizada, mas num arranjo de desmobilização de solicitações coletivas. Estabelecidos os pressupostos representativos, pressupõe-se que a dívida histórica esteja paga, mesmo que um contingente significativo de pessoas seja destituído da situada oportunidade, ao mesmo tempo em que são desviados os eixos de discussão acerca de uma sociedade democratizadora e democratizante em sentido universalizado e ratificado o compromisso com a construção de perfil de homem universal sim, mas para uma sociedade determinada: a capitalista, promotora de mercados e cidadãos consumidores. Dentre as políticas compensatórias, para efeitos do nosso objeto, destacam-se as políticas de cotas para acesso à universidade de grupos socialmente desfavorecidos, no caso do Brasil, de negros, indígenas e pobres.

\section{Desafios contemporâneos à inclusão social de classes menos favorecidas à universidade}

Este trabalho, portanto, procura evidenciar e promover a denúncia do jogo de interesses do capital globalizado, que distante de favorecer quaisquer mudanças estruturais para a emancipação e libertação do sujeito social, universalizando sua condição de sujeito histórico, cunha artifícios para a ratificação de sua ideologia em nome da atenuação das tensões sociais, quer por meio de promoção de fundos de inversão para causas pontuais, quer pela indução de programas sociais condicionados aos empréstimos de organismos multilaterais ao estados nacionais. Casanova (2001, p.46) chama a atenção para o fato de que:

Estamos num clima ideológico em que se enfraqueceram as propostas da "soberania nacional" em favor das propostas da "globalidade" e na qual se obscureceram os direitos "dos povos" diante dos direitos dos "indivíduos". Também houve mudança no desprestígio da "justiça social", conceito ao qual se opõe a "justiça", já desprovido de adjetivo... As "lutas de libertação" e as "lutas de classes" aparecem como um fenômeno terminado, como conceitos obsoletos. Em vez da "libertação" propõe-se a "inserção" ou a "integração", e, em vez da luta social, a "solidariedade" humanitária ou empresarial.

Neste sentido o maior desafio da universidade está na atitude, como instituição social, de despertar e fazer despertar uma outra consciência, não num plano utópico, mas da leitura da recorrência sociais não excludentes, da vida para a vida. Marx \& Engels (1987) vão afirmar que a produção de idéias, de representações e da consciência está em primeiro lugar direta e intimamente ligada à atividade material e ao comércio material dos homens; é a linguagem da vida real, logo, não é a consciência que determina a vida, mas a vida que determina a consciência. Desta construção, as idéias produzidas pelo aparelho de Estado precisam ser contextualizadas, as intencionalidades questionadas à medida em que a atuação do homem sobre o mundo vivido, constitua-se na organização do conhecimento e intervenções pertinentes, como produto de múltiplas determinações. Este é o maior desafio, dado que todas os organismos na relação capital-trabalho reforçam o inverso. 


\section{A universidade no Brasil a partir de uma dimensão universal sustentada por uma lógica democrática, libertadora e humanizadora}

Recuperar o sentido da consciência coletiva como resposta ao processo de expropriação de direitos sociais, dentre os quais o da educação superior numa dimensão universalizada é uma tarefa em construção que não pode ser deixada em segundo plano e nem negociada por medidas paliativas que pretendem, em nome da "minimização de distorções sociais", conservar a estrutura capitalista do controle social de mentes e corpos. A consciência coletiva aprimora os relacionamentos na consecução de objetivos comuns, pois coloca como ponto de partida a participação de todos os atores sociais envolvidos com a universidade e seu entorno. Esta consciência é gerada num espaço democrático, em que os sujeitos sentem-se parte indissociável da história na e da tomada de decisão sobre o seu destino. Neste quadro, as solicitações são analisadas em profundidade e a participação se materializa por meio do exercício do direito de vez, voz e voto. É a partir da consciência coletiva que surgem e são encaminhados os seguintes questionamentos: quem somos? onde estamos e qual é a finalidade do desenvolvimento do nosso trabalho? como aperfeiçoar a nossa ação interventiva de forma a promover a melhoria de qualidade do que produzimos sem ferir e expropriar o direito universal dos demais? como nos posicionamos politicamente frente as crises do mundo contemporâneo e por meio de seus condicionantes provocamos a crítica-reflexiva? Em que grau e em que medida a universidade contribuir efetivamente para a emancipação do indivíduo e para o exercício pleno de sua cidadania? Em que pese nem todas estas questões serem respondidas, procurar-se-á por meio das contribuições de Mészáros, Habermas, Kosik, Adorno \& Horkheimer o desenvolvimento de algumas problematizações recorrentes para a temática da inclusão social à universidade na atualidade.

\section{A universidade e as práticas dissimuladoras na centralidade capital-trabalho a partir de Mészáros}

A geração das desigualdades, fome, desemprego, preconceitos são temas amplamente discutidos na sociedade mundial como fatores agravantes do desenvolvimento econômico, subtraindo possibilidades de redistribuição de renda e a promoção da justiça social. Exatamente nesta direção que não é possível ignorar a discussão de ações afirmativas como meio de inclusão educacional à universidade brasileira alienada da lógica do capital e do capitalismo. Daí a importância de destacarmos esta problematização sob uma ótica não reducionista ao longo deste trabalho. Como lembra Antunes (2002) a partir de Mészáros (2005):

Como um dos eixos centrais de sua interpretação particular do fenômeno, Mészáros considera capital e capitalismo como fenômenos distintos. A identificação conceitual entre ambos fez com que todas as experiências revolucionárias vivenciadas no século passado, desde a Revolução Russa até as tentativas mais recentes de constituição societal socialista, se revelassem incapacitadas para superar o "sistema de sociometabolismo do capital", isto é, o complexo caracterizado pela divisão hieráquica do trabalho, que subordina suas funções vitais ao capital. $\mathrm{O}$ capital antecede ao capitalismo e é a ele também posterior. O capitalismo, por sua vez, é uma das formas possíveis de realização do capital, uma de suas variantes históricas, como ocorre na fase caracterizada pela subsunção real do trabalho ao capital. Assim como existia capital antes da generalização do 
sistema produtor de mercadorias, do mesmo modo pode-se presenciar a continuidade do capital após o capitalismo, pela constituição daquilo que Mészáros denomina como "sistema de capital pós-capitalista", que teve vigência na URSS e demais países do Leste Europeu, durante várias décadas do século XX. (Sublinhado nosso)

Quando das proposições advindas de uma indústria cultural forjada pelo capitalismo em relação à inclusão educacional, percebe-se nitidamente que não existe grau de isenção sobre sua intencionalidade, isto é, o comprometimento com os interesses do capital. A ideologia em sentido restrito transveste-se na incorporação de atendimento às necessidades das demandas, “[...] no assistencialismo e nas políticas compensatórias, sem caminhar absolutamente nada na distribuição das riquezas socialmente produzidas" (SANFELICE, 2006, p. 37). Portanto, o que vale é o controle das tensões sociais por meio de medidas paliativas, tendo em vista a consecução do ideário neoliberal e como diz o próprio Mészáros (2005, p.45) a educação desenvolvida na lógica do capital consegue "[...] produzir tanta conformidade ou 'consenso' quanto for capaz, a partir de dentro e por meio dos seus próprios limites institucionalizados e legalmente sancionados". O caminho para a emancipação da educação e oportunidades educacionais, inclusive na universidade, é o rompimento com a lógica capitalista na universalização da educação e trabalho como atividade humana auto-realizadora. Neste encaminhamento Mészáros (Idem, p.27) conclui que limitar "[...] uma mudança educacional radical às margens corretivas interesseiras do capital significa abandonar de uma só vez, conscientemente ou não, o objetivo de uma transformação social qualitativa".

\title{
A universidade e o agir comunicativo na determinação da ação histórica em Habermas
}

Para Habermas (1997) se o procedimento democrático fundamenta a legitimidade do direito, certamente podemos inferir que a legitimidade do direito deve assegurar o procedimento democrático. No caso, as categorias direito e democracia devem estar intrinsecamente relacionadas em todo o momento a ponto de assegurar a universalização e participação do que se conhece como oportunidades necessárias e igualitárias da vida social. Assim, entendemos que uma ação comunicativa em nível democrático, universal e humano, promotor e garantidor da equidade e igualdade propriamente ditas, não pode aceitar medidas pseudo-corretivas que negam o direito cidadão e o espírito democrático, pois:

\begin{abstract}
Uma ordem jurídica não pode limitar-se apenas a garantir que toda pessoa seja reconhecida em seus direitos por todas as demais pessoas; o reconhecimento recíproco dos direitos de cada um por todos os outros deve apoiar-se, além disso, em leis legítimas que garantam a cada um liberdades iguais, de modo que "a liberdade do arbítrio de cada um possa manter-se junto com a liberdade de todos". (HABERMAS, 2003, p.52)
\end{abstract}

Se de fato se pensasse a equidade e igualdade de maneira universalizada como aponta Habermas, não haveria discriminação em suas distintas manifestações, pois não é suficiente reconhecer as diferenças, é necessário garantir as condições para suas viabilizações. A universidade tem sido objeto de distintas discussões, apresentando posicionamentos diversos, incluindo aqueles que insistem que o processo de expropriação histórica é mais cultural do que sócio-econômico, sem se ater na totalidade da relação 
capital-trabalho que efetivamente promove a manutenção da não-universalização, mesmo em face de um discurso que afirme o contrário. Qual o caminho? Recuperar o sentido entre direito, democracia, universalização e humanização como objetos inalienáveis da história e manifestações humanas que não se dará de forma gratuita ou naturalmente, mas por meio da manifestação do homem na história e com a história, objeto que embora debatido exaustivamente na academia e sociedade carece de maiores aprofundamentos, pois é uma questão não resolvida frente à estrutura social do capitalismo.

\title{
A universidade e a dialética do concreto a partir de Karel Kosik
}

Entender e encaminhar a universalização, democratização e humanização do homem que elabora o seu conhecimento histórico e que se autoproduz é a grande necessidade para tornar a sociedade em geral num espaço comum, sem exclusão, bem como as suas instituições sociais, como, por exemplo, a universidade. Neste sentido, é oportuno destacar a leitura do mundo vivido por meio de uma dialética do concreto que se situa em todos os espaços sociais. Exatamente por isto é que não é admissível pensar as ações afirmativas como respostas finais de acesso aos grupos desfavorecidos à universidade. Se a práxis é possível, a produção do mundo, bem como a autoprodução do homem não devem ser excludentes, ao contrário:

\begin{abstract}
A práxis na sua essência e universalidade é a revelação do segredo do homem como ser ontocriativo, como ser que cria a realidade (humanosocial) e que, portanto, compreende a realidade (humana e não-humana, a realidade na sua totalidade). A práxis do homem não é atividade prática contraposta à teoria; é determinação da existência humana como elaboração da realidade. (KOSIK, 1985, p.202)
\end{abstract}

Assim, podemos afirmar que a universalização, democratização e humanização da universidade, oportunizando os mesmos direitos indistintamente, não é uma dimensão em si e, conseqüentemente, um privilégio para poucos, mas constitui-se numa das dimensões do savoir-faire humano, portanto, na medida da autoprodução de sua realidade, contrapondo-se ao segregacionismo e outros "ismos" que reduzem e coisificam os homens em estratos específicos, consoante interesses particularistas. Dito de outra maneira, à medida que o homens produz a realidade e participa de suas múltiplas determinações, não deverá ser expropriado deste processo, nem mesmo de maneira parcimoniosa, sob o risco de alienação de seu direito e identidade. O que se coloca na atualidade com a proposta da discriminação positiva é a proposição do mundo da pseudoconcretidade, isto é, o mundo da alienação, portanto, do afastamento da leitura correta que deveria ser desenvolvida. Há que se resgatar em sua totalidade um maior despertamento por meio da dialética do concreto, de uma análise crítica das tentativas forjadas para a mostração de um mundo diferente do real, o que certamente vem ocorrendo no Brasil, mas que ainda precisa de maior fôlego para um maior encampamento horizontalizado.

\section{A universidade e o antagonismo entre o particular e o universal a partir de Adorno \& Horkheimer}

Uma visão pontuada pelo olhar crítico sobre o fenômeno histórico-social não pode ser dissociada do antagonismo existente entre o particular e o universal, no caso deste trabalho sobre as ações afirmativas como meio de acesso para as classes desfavorecidas à 
universidade, ou seja, não deve tomar a inclusão educacional simplesmente como uma questão de opção ou da chamada "consciência social" em nome dos valores humanos e das reparações compensatórias historicamente situadas (dimensão particularizada), mesmo que por meio de modelos internacionais, sem considerar a necessidade de uma ruptura radical com a lógica do capital. Qualquer posicionamento nesta lógica concorre para a negação de uma dimensão mais ampla das mudanças educacionais comprometidas com a emancipação dos sujeitos sociais e com a construção de sociedades mais justas e igualitárias... (PESCE, 2007). Neste processo de conscientização por uma lógica universalizada, libertadora e emancipadora, vale lembrar que:

Caso queiramos pensar a inclusão educacional no Brasil..., o desafio é bem maior. É preciso pensar esta sociedade como um todo e avaliar as condições históricas objetivas que nos disponibilizam, num trabalho coletivo, avançar em direção ao novo. Não um novo qualquer, mas um novo que supere qualitativamente o status quo de hoje. O problema não é legal e/ou formal. É um problema de fundo. Sem a superação da exploração do trabalho pelo capital, nada se transformará. Tudo se reproduzirá e as políticas inclusivas não perderão seu caráter sempre paliativo. (SANFELICE, 2006, p.39)

Neste âmbito Adorno \& Horkheimer (1985) apontam que o verdadeiro esclarecimento não mais pode ser entendido numa ingênua perspectiva mítica entre o 'bem' e o 'mal' ou entre o 'mal menor' e o mal maior', mas como base para tirar o homem de seu processo de alienação ou de sua menoridade e não mais ser conduzido, mas conduzir a construção de sua própria história. Em relação a particularização da justiça em detrimento da universalização da equidade, tomando as ações afirmativas como ponto de análise, podemos afirmar que, a aceitação tácita de sua proposição particulariza e condiciona uma tipologia de sociedade (de caráter mítico) negligenciando, conseqüente e convenientemente, a universalização de oportunidades. Desta forma, o abismo entre o particular e universal permanece, restando a ilusão de horizontalidade.

\section{Considerações finais}

Com a redefinição do papel do Estado como agente regulador do mercado e políticas públicas foram desenvolvidas reformas nas políticas para o Ensino Superior, situando a lógica capital-trabalho como fio condutor. Na década de 90 a reestruturação produtiva, a reforma do Estado e as políticas educacionais, por meio da administração gerencial incluirá na pauta do dia as orientações de organismos multilaterais conforme a disposição neoliberal quase em sua totalidade: produção acadêmica, formação do profissional da educação, diminuição da pobreza, atenção aos focos de conflitos sociais, atenuação das desigualdades, dentre outros.

Em meio a este processo reformista, muitos movimentos passaram a ter maior visibilidade, solicitando políticas de equidade nas oportunizações sociais, principalmente quanto ao acesso à universidade brasileira. Direcionada pela influência neoliberal, a contrapartida do Estado, preservou a estrutura de controle e para desmobilizar os grupos propôs as ações afirmativas, sinônimas de "discriminação positiva", a exemplo do que os EUA desenvolveram: inicialmente para os negros, estendendo depois para os indígenas e, de forma delimitada para alunos de escolas públicas por meio das denominadas "cotas". O resultado dividiu as opiniões dentro e fora da academia marcadamente por dois extremos: os favoráveis e os contrários. Entretanto, um terceiro olhar sobre tais proposições nos 
mostra que tais medidas se mostram paliativas projetando um processo maior de exclusão e descaso com os grupos étnicos e classes sociais menos favorecidas.

A lógica capital-trabalho não coloca em discussão a dimensão universal sustentada por uma lógica libertadora e humanizadora, mesmo porque tem como resolvidos os conflitos sociais emersos negando a ação comunicativa entre individualidade e coletividade (HABERMAS, 2003), o distanciamento entre justiça e equidade e reflexão sobre a realidade concreta da humanidade e de sua construção histórica (KOSIK, 1985), bem como alienando os homens numa dimensão ainda mítica, de um esclarecimento determinado e controlável proposto como eixo salvacionista e não-emancipatório. E finalmente com Mészáros (2005, 2006, 2007), observamos que o exercício da educação superior somente alcançará uma dimensão humanizadora, democrática e universal quando não se limitar à medidas paliativas, que se preocupam muito mais em esvaziar as vozes do que promover uma transformação social verdadeiramente qualitativa.

\section{Referências}

ADORNO, T.W. \& HORKHEIMER, M. Dialética do esclarecimento. Rio de Janeiro: Zahar, 1985.

ANDERSON, P. Balanço do neoliberalismo. In SADER, E. \& GENTILI, P. Pósneoliberalimo: as políticas sociais e o Estado democrático. Rio de Janeiro: Paz e Terra, 2000 .

ANTUNES, R. Para além do capital e de sua lógica destrutiva. In Revista Espaço Acadêmico, Ano II, $\mathrm{N}^{\mathrm{o}}$ 14, julho, 2002.

BRASIL. Grupo de Trabalho Interministerial para a Valorização da População Negra. Brasília: Ministério da Justiça, 1996.

BRESSER PEREIRA, Luis Carlos. Da administração pública burocrática à gerencial. Revista do Serviço Público, Ano 47, Volume 120, № 1, 1996.

CASANOVA, P. G. Globalidade, neoliberalismo e democracia. In GENTILI, P. (Org.). Globalização excludente: desigualdade, exclusão e democracia na nova ordem mundial. Petrópolis/RJ: Vozes, 2001.

CHAUÍ, M. Neoliberalismo e universidade. In OLIVEIRA, F. \& PAOLI, M. C. (Orgs.). Os sentidos da democracia: políticas do dissenso e hegemonia global. 2.ed. Petrópolis, R.J: Vozes: NEDIC, 2000.

CORAGGIO, J.L. Propostas do Banco Mundial para a educação: sentido oculto ou problemas de concepção? In: DE TOMMASI, L: WARDE, S. (orgs). O Banco Mundial e as políticas educacionais. São Paulo: Cortez, 1996.

CUNHA, L. A. A universidade reformanda: o golpe de 64 e a modernização do ensino superior. Rio de Janeiro: Francisco Alves, 1988.

Educação e desenvolvimento social no Brasil. 5a Ed. Rio de Janeiro, 1989.

Educação, Estado e democracia no Brasil. São Paulo: Cortez Editora; Niterói: EDUFF; Brasília: FLACSO, 1991.

HABERMAS, J. Direito e democracia: entre facticidade e validade. Trad. Flávio Beno Siebeneichler. 2. ed. vol. I. Rio de Janeiro: Tempo Brasileiro, 2003.

KAUFMANN, R. F. M. Ações afirmativas à brasileira: necessidade ou mito? A implementação para negros como mecanismo concretizador de direitos fundamentais. Uma análise históricojurídico-comparativa do negro nos Estados Unidos da América e no Brasil. In Jus Navigandi, 
Teresina, ano 11, n. 1455, 26 jun. 2007. Disponível em: $<$ http://jus2.uol.com.br/doutrina/texto.asp?id=10070>. Acesso em: 07 jun. 2009.

KOSIK, K. Dialética do concreto. Rio de Janeiro: Paz e Terra, 1985.

LIMA, P. G. Unha de gato em novelo de lã ou do financiamento da pesquisa científica e tecnológica no governo FHC: o dito e o feito no plano real (1994-2002). Tese de Doutorado. Araraquara/SP: Universidade Estadual Júlio de Mesquita Filho/FCLAR.

MARX, K. \& ENGELS, F. A ideologia alemã (Feuerbach). $6^{\text {a }}$ ed. Trad. de José Carlos Bruni \& Marco Aurélio Nogueira. São Paulo: Hucitec, 1987.

MÉSZÁROS, I. A educação para além do capital. São Paulo: Boitempo, 2006.

O desafio e o fardo do tempo histórico. São Paulo: Boitempo, 2007.

2005.

Para além do capital: rumo a uma teoria de transição. São Paulo: Boitempo,

PESCE, L. As contradições da institucionalização da educação a distância, pelo Estado, nas políticas de formação de educadores: resistência e superação. Tese (Pós-doutoramento). Campinas: FE/Universidade Estadual de Campinas, 2007.

SANFELICE, J. L. Inclusão educacional no Brasil: limites e possibilidades. In Revista de Educação da PUC-CAMPINAS, Nº 21, p. 29-40, novembro de 2006.

Movimento estudantil: a UNE na resistência ao golpe de 64. São Paulo: Cortez Editora; Editora Autores Associados, 1986.

SILVA, G. M. D. da. Ações afirmativas no Brasil e na África do Sul. In Tempo Social, Revista de sociologia da USP, v. 18, n. 2, 2006.

SILVA, M. A. da. Intervenção e consentimento: a política educacional do Banco Mundial. São Paulo: Autores Associados, 2002.

SILVEIRA, N. D. R. Universidade brasileira: a intenção da extensão. São Paulo: Loyola, 1987.

WEBER, M. The social psychology of the world religions . In: GERTH, H. \& MILLS, C. (eds.), From Max Weber. Nova York, Oxford University Press, 1946.

XAVIER. M. E. S. P. Capitalismo e escola no Brasil: a constituição do liberalismo em ideologia educacional e as reformas do ensino (1931-1961). Campinas (SP): Papirus, 1990.

Notas:

\footnotetext{
${ }^{1}$ Docente do PPGEdu da Faculdade de Educação da Universidade Federal da Grande Dourados -UFGD. Email: paulolima@ufgd.edu.br

${ }^{2}$ Trata-se do governo de Fernando Henrique Cardoso, filiado ao Partido da Social Democracia Brasileira (PSDB), cujo ícone emblemático é o "tucano", pássaro da fauna brasileira.
}

Artigo recebido em: 09/07/09

Aprovado em: 26/05/10 